\title{
A construção do sentido em interações verbais na rádio em Português Europeu: mecanismos discursivos em narrativas de experiência de vida
}

The Construction of Meaning in Verbal Radio Interactions in European Portuguese: Discursive Mechanisms in Life Experience Narratives

\author{
Carla Aurélia de Almeida* \\ calmeida@uab.pt \\ https://orcid.org/0000-0003-1682-5106
}

\begin{abstract}
Resumo
Tendo por base um corpus de interações verbais realizadas na rádio em Portugal, o presente artigo analisa o modo como, nestes discursos, se estrutura o processo de construção do sentido. Para o efeito, considera o quadro enunciativo, as sequências de atos de discurso e as estratégias discursivas que permitem atribuir credibilidade e legitimidade ao discurso, captando a atenção. Analisam-se aspetos semânticos e pragmáticos da construção de narrativas de experiência de vida: as falas justapostas, as repetições, o uso da expressão aproximativa "e tal", o uso de "pronto" como marcador discursivo, a ocorrência de identidades na fala e a realização de asserções avaliativas. Neste contexto, consideram-se atos de autoelogio com mitigadores e com o recurso ao uso do verbo declarativo dizer na terceira pessoa do plural para minimizar a ameaça da face. Analisam-se ainda os comentários de avaliação que denotam a escuta atenta, permitindo fazer a gestão das trocas interacionais.
\end{abstract}

Palavras-chave: Estratégias discursivas; Autoelogio; Emoção na interação; Identidades na fala; Mitigação.

\section{Abstract}

Based on a corpus of verbal interactions carried out on radio in Portugal, this article examines how, in these speeches, the process of constructing meaning is structured. To this

Professora Auxiliar do Departamento de Humanidades da Universidade Aberta - DH-UAb - e Investigadora do Instituto de Sociologia da Universidade do Porto - IS-UP, Porto, Portugal. 
end, it considers the enunciative framework, the sequences of speech acts and the discourse strategies that enable to attribute credibility and legitimacy to the discourse, capturing attention. Semantic and pragmatic aspects of the construction of life experience narratives are analysed: juxtaposed speech, repetitions, the use of the approximate expression "e tal", the use of "pronto" as a discourse marker, the occurrence of identities in talk and the production of evaluative assertions. In this context, acts of self-praise with mitigators and the use of the declarative verb "dizer" in the third person of the plural to minimize the threat of the face are considered. Evaluation comments that denote attentive listening are also analysed, allowing for the management of interactional exchanges.

Keywords: Discursive Strategies; Self-praise; Emotion in Interaction, Identities in Talk, Mitigation.

\section{Introdução}

O enfoque teórico e metodológico deste trabalho é orientado por uma perspetiva semântico-pragmática (VERSCHUEREN, 1998, p. 236) da organização e do funcionamento do discurso produzido em programas constituídos por conversas na rádio (radio phone-in programs), que se realizaram no período noturno em Portugal (ALMEIDA, 2012). Procederemos à análise do modo como se coconstrói o sentido nestes contextos mediáticos, com a frequente irrupção de narrativas de experiência de vida e com o constante uso de estratégias discursivas de gestão das trocas interacionais.

No contexto mediático em análise, impõe-se o estudo do contrato de comunicação (CHARAUDEAU, 1995, p. 99), destacando a relevância da realização de práticas discursivas específicas que visam atingir objetivos de legitimidade, de credibilidade e de captação. Neste âmbito, analisaremos as ações discursivas que concorrem para estes objetivos: (i) as asserções avaliativas produzidas em intervenções de ouvintes; (ii) as asserções realizadas por locutores de rádio, com múltiplas funções na estrutura conversacional e (iii) as narrativas interativas ou histórias de vida que os ouvintes realizam em diálogo com os locutores de rádio.

Em intervenções iniciativas de ouvintes, iremos verificar que as asserções avaliativas apresentam, no seu conteúdo proposicional, a indicação de pertença a variáveis como sexo e categoria socioprofissional dos participantes e que se inscrevem em "esquemas sociais" convencionais (GIBBS, 1985, p. 98), contribuindo para a construção de um discurso testemunhal e credível que capta a atenção do auditório destes programas. Procuraremos demonstrar que a verbalização da pertença a comunidades particulares no seio de asserções avaliativas, como as que se agrupam em função dos parâmetros anteriormente assinalados, constitui uma estratégia de atribuição de credibilidade ao discurso, legitimando, argumentativamente, o discurso proferido pelos ouvintes. Com efeito, as identidades discursivas (ANTAKI; WIDDICOMBE, 1998) convocadas pelos participantes são reveladas pertinentes para a determinação da sequencialidade discursiva: os ouvintes, regularmente, assumem uma posição de expert na matéria em discussão, para legitimarem a expressão de opiniões e a irrupção de narrativas de experiência de vida que se tornam, assim, pertinentes para 
o tema da emissão, permitindo enquadrar as histórias de vida (narradas pelos ouvintes que entram na emissão) num lugar vivido e testemunhal.

Por seu lado, os locutores de rádio realizam intervenções reativas, proferindo asserções que têm diversas funções na estrutura conversacional: (i) intervenções de continuidade (ii) intervenções de relance do tema; (iii) intervenções diretrizes (ALMEIDA, 2012, p. 224-229). Todas estas funções contribuem para a construção de narrativas de experiência de vida e demonstram um cuidadoso trabalho de gestão das trocas interacionais nestes contextos mediáticos. Deste modo, as narrativas que ocorrem nestes contextos demonstram que o sentido é compartilhado entre os interactantes e constitui uma ação conjunta testemunhal que visa prender a atenção do auditório.

Em suma, procuraremos demonstrar que o discurso inscrito em narrativas orais que irrompem nestes contextos de programas de rádio tem um carácter testemunhal (THORNBORROW, 2001), apresentando estratégias discursivas que são específicas destes contextos.

\section{Alguns pressupostos analíticos: os corpora mediáticos e a abordagem descritiva do material empírico}

No domínio das Ciências da Linguagem, em geral, e da Análise do Discurso, em particular, os estudos da Linguística enunciativo-discursiva que analisam a organização e o funcionamento dos discursos que ocorrem nos media têm tido implicações importantes para o desenvolvimento de uma consciência crítica de interpretação do sentido do texto/discurso que ocorre em diversos suportes mediáticos. Neste âmbito de análise, há uma multiplicidade de perspetivas que tem como prioridade o estudo das formas dialogais e, no seu seio, encontramos uma diversidade de métodos. Por exemplo, no âmbito da Lexicometria, com enfoque na análise de textos políticos e de diferentes tipos de corpora textuais que ocorrem no espaço dos media (BONNAFOUS; TOURNIER, 1995: 67-68), fazendo uma reflexão sobre os media, o espaço público, a receção, entre outras questões e tendo como enfoque analítico o dispositivo enunciativo, argumentativo e pragmático (BONNAFOUS; TOURNIER, 1995: 78). Assim, os investigadores em Análise do Discurso trabalham os fenómenos linguístico-discursivos que têm apenas pertinência em relação ao corpus estudado, considerando que "as hipóteses sobre os papéis respetivos das estratégias e das ideologias são diferentes e, por conseguinte, os corpora e os questionamentos" (BONNAFOUS; TOURNIER, 1995, p. 80, tradução nossa). Neste âmbito, torna-se muito pertinente a afirmação de Dominique Maingueneau sobre a constante interação entre o corpus e o analista, salientando que o corpus constituído e delimitado leva o analista a reformular as suas questões e a redefinir o seu corpus (MAINGUENEAU, 1991, p. 7).

O presente estudo considera um corpus oral em Português Europeu constituído por interações em programas de rádio interativos (ALMEIDA, 2012). Para esse efeito,

\section{LINHA D'ÁGUA}


selecionamos interações realizadas no programa Boa Noite $(\mathrm{BN})$, emitido entre as zero e as duas horas, de todos os dias úteis. A estrutura deste programa configura-se em torno de conversas com os ouvintes que obedecem sistematicamente a um tema previamente introduzido por um locutor de rádio do sexo feminino: os ouvintes entram em antena para falar de um tópico previamente estabelecido (temas como "Os livros", "A preguiça", "O conflito de Gerações", “A Regionalização”, entre outros), selecionado pela locutora de rádio. Na análise deste material empírico, teremos em consideração a reflexão de Patrick Charaudeau (1995) sobre a constituição de um "corpus de textos reunidos em nome de um tipo de situação (contrato) que os determina e nos quais estudamos as constantes (para definir um género), e as variantes (para definir uma tipologia de estratégias possíveis)" (CHARAUDEAU, 1995, p. 106, tradução nossa). As análises linguístico-discursivas de corpora específicos dos media têm, pois, como quadro de investigaçã,o restrições impostas pelo contrato de comunicação. Neste âmbito, para que se efetive a troca interacional entre dois interlocutores,

(...) é preciso que eles tenham em comum universos de referência (saberes partilhados) e finalidades (motivações comuns) diferentes, porque o outro só é perceptível e identificado na dissemelhança e apenas em cada papel particular: (...) o sujeito comunicante (...) e o sujeito que interpreta. Assim, este princípio diz que cada um dos parceiros está empenhado num processo recíproco (mas não simétrico) de reconhecimento do outro, numa interação, legitimando-o ao mesmo tempo no seu papel, o que é uma condição de validação do ato de discurso. Este princípio cria o aspecto contratual de todo o ato de comunicação, uma vez que implica um reconhecimento - legitimação de cada um dos parceiros em relação ao outro (CHARAUDEAU, 1995, p. 99, tradução nossa).

Nestes “espaços de estratégia abertos pela situação de comunicação (de legitimação, de credibilidade e de captação)" (CHARAUDEAU, 1995, p. 107-108, tradução nossa), a consideração das estratégias discursivas particulares que ocorrem no contexto mediático permite-nos perspetivar a natureza comunicativa dos processos interpretativos que têm por base o envolvimento conversacional (GOFFMAN, 1981; GUMPERZ, 1989, p. 2; TANNEN, 1989) que ocorre entre locutor e alocutário e que, para autores como Gumperz, constitui a chave para a intercompreensão no discurso:

[...] a compreensão pressupõe o envolvimento conversacional. Uma teoria geral das estratégias discursivas tem, por conseguinte, de começar por especificar os conhecimentos linguísticos e socioculturais que têm de ser partilhados para se manter o envolvimento conversacional e depois terá de lidar com a determinação dos aspetos da inferência conversacional que levam à especificidade cultural, subcultural e situacional da interpretação (GUMPERZ, 1982, p. 2-3, tradução nossa)

No presente texto, colocaremos, assim, o enfoque analítico nas "expectativas partilhadas" que são abertas pelos "quadros" ("scripts") ou "esquemas" (GUMPERZ, 1980, p. 103-104) de emissões noturnas na rádio em Portugal e consideraremos de que modo, neste contexto mediático, ocorrem estratégias discursivas específicas que contribuem para a eficácia interacional. 


\section{O quadro interacional de programas de rádio e o envolvimento conversacional dos participantes no jogo verbal}

Os interlocutores de uma interação pautam-se por normas de interação - esquema participativo - que acionam em função de um tema comum e de acordo com a interpretação dos dados da memória compartilhada (VAN DIJK, 1985, p. 75; ALMEIDA, 2012, p. 63). Estes três aspectos - esquema participativo, unidade de tempo e de lugar, tema comum - constituem, de acordo com Kerbrat-Orecchioni (1998, p. 245), os três critérios que permitem delimitar uma interação.

Com efeito, já E. Goffman (1987) destacava que os atores sociais põem em jogo um "foco de atenção comum", de tal forma que o importante numa conversação são "as enunciações frequentemente feitas para produzir outras ou para servir como respostas verbais às suas produções" (GOFFMAN, 1987, p. 81). Na análise da conversação, Goffman destaca a noção de "jogo verbal" que os participantes desenvolvem, analisando o que chama de "movimentos conversacionais", (GOFFMAN, 1987, p. 82) que permitem "tantos movimentos e contra-movimentos afirmativos, vaivém ao qual o nome de jogo mútuo conviria, sem dúvida, mais do que o de diálogo" (GOFFMAN, 1987, p. 82, tradução nossa). Os constrangimentos rituais são, assim, decompostos em movimentos (GOFFMAN, 1987). Com esta última noção, Goffman destaca a "flexibilidade da conversação", passando a focalizar a interação com base nas noções de intervenção iniciativa e de intervenções reativas (ALMEIDA, 2014, p. 95).

Assim, no quadro interacional criado pelo(a) locutor(a) de rádio, os ouvintes e o auditório (trocas triádicas), as atividades discursivas que ocorrem denotam um esquema participativo, regularmente, feito por heterosseleção: os intervenientes são selecionados pelos profissionais de antena (CHARAUDEAU, 1984, p. 29), que fazem a triagem dos telefonemas que entram na emissão, e os locutores de rádio desempenham um papel ativo na dinâmica das trocas, fazendo a gestão do tempo de emissão, dando a vez de elocução e zelando pela manutenção de coerências semântico-pragmáticas interdiscursivas com estratégias de alinhamento que visam enfatizar o tema da conversa (ALMEIDA, 2012, p. 92). Como iremos ver, no quadro enunciativo destes programas de rádio com um cariz testemunhal, o discurso dos ouvintes apresenta um estilo de grande envolvimento (TANNEN, 2001) responsável por sobreposições da fala, hesitações e repetições e pela irrupção de narrativas de experiência de vida. Estes fenómenos discursivos revelam a emoção (PLANTIN et al., 2000) dos interactantes que participam nestas emissões na rádio. Com efeito, na linha de Derek Edwards (2001, p. 236), a expressão da emoção pode ser analisada tendo por base o trabalho interacional (GOFFMAN, 1987), isto é, através da análise das estratégias discursivas (GUMPERZ, 1989) que criam o "envolvimento conversacional" (GUMPERZ, 1982, p. 2-3). Esta última noção baseia-se nas ações discursivas dos participantes que enfatizam a natureza interativa da interação conversacional e é baseada na concepção de que a interpretação do sentido é uma construção conjunta realizada entre locutor e alocutário (GUMPERZ, 1982, p. 2-3).

\section{LINHA DÁGUA}


Assim, através da interface entre teoria e análise empírica, teremos em consideração as características semânticas e pragmáticas de narrativas interativas orais desenvolvidas em programas de rádio em Português Europeu, destacando os fenómenos discursivos que denotam o envolvimento conversacional (TANNEN, 1989; GUMPERZ, 1989) dos interactantes e a emoção dos participantes no jogo interacional (GOFFMAN, 1967, tradução nossa). Mais especificamente, a nossa atenção estará orientada para: (i) a justaposição das falas e os segmentos relatados em discurso indireto livre intercalados com segmentos relatados em discurso direto; (ii) os comentários metadiscursivos que revelam a escuta atenta dos alocutários; (iii) as repetições lexicais e sintáticas; (iv) as digressões temáticas (ANDRÉLAROCHEBOUVY, 1984, p. 115) e (v) o uso de diminutivos como estratégia de aproximação.

\section{As estratégias discursivas em narrativas de experiência de vida no discurso interativo oral de programas de rádio}

$\mathrm{Na}$ análise do oral interacional, verificamos que, regularmente, as narrativas surgem encaixadas nas conversações (SACKS, 1995; GOODWIN, 1981), destacando-se, na linha de Kerbrat-Orecchioni (1998, p. 129), as características fluidas na construção de uma tipologia das interações. Com efeito, segundo esta última autora, um dos eixos de caracterização dos tipos de interação diz respeito à natureza da macroestrutura que pode ser argumentativa, descritiva ou narrativa, e o problema reside no facto de uma estrutura - argumentativa, descritiva ou narrativa - dificilmente constituir a totalidade de uma interação. Com efeito, regularmente, nestes contextos mediáticos, as chamadas "narrativas orais quotidianas" (LACOSTE, 1986, p. 52) irrompem espontaneamente em situação de interação e, sendo testemunhais, abrem-se à variedade de temas (ALMEIDA, 2011, p. 46).

Em situação de interação em programas de rádio, constituídos por ouvintes que telefonam para as emissões, é comum a irrupção de narrativas de experiência de vida com um carácter vivido ou testemunhal (THORNBORROW, 2001). O envolvimento conversacional dos participantes que as expressam é revelado pelas constantes manutenções da vez de elocução, pelas repetições e também pelas digressões temáticas.

Estas narrativas partilham características específicas das "histórias conversacionais" que ocorrem noutros contextos interacionais (NORRICK, 2010, p. 2; OCHS; CAPPS, 2001) ou "histórias faladas" (TANNEN, 1986, p. 323), como o constante recurso ao discurso humorístico e aos risos, que possibilitam a acomodação intersubjetiva (ALMEIDA, 2012, p. 172) entre as faces dos interactantes. Como iremos ver, o discurso das narrativas de experiência de vida que ocorrem nos programas de rádio em análise apresenta aspetos formais específicos que denotam a construção conjunta (a coconstrução) do texto conversacional (TANNEN, 1989; TANNEN, 2001): as repetições, as asserções avaliativas com valor axiológico positivo e os enunciados em simultâneo constituem estratégias de cooperação desenvolvidas pelos participantes nestas interações e permitem a coconstrução do sentido em interação.

\section{LINHA D'ÁGUA}


Com efeito, as ações, os mecanismos discursivos e as estratégias discursivas que ocorrem nos discursos proferidos por interactantes específicos em quadros interacionais particulares (como são os que se realizam nos media) constituem códigos e normas conhecidas pelos falantes que assinalam a pertença a um grupo (ou comunidade) particular: "Cada comunidade tem os seus próprios jogos rituais (ou normas) locais e específicos que podem ser explorados para objetivos sociais e interpessoais" (DIAMOND, 1996, p. 77, tradução nossa).

Nas histórias de vida que irrompem nestes contextos, há assim “jogos rituais” que são revelados na produção de elementos de "intimidade" na expressão de histórias de vida que criam o chamado "small talk" (COUPLAND; JAWORSKI, 2003, p. 85-87), demonstrando o papel afetivo e social que estas narrativas têm na construção de uma comunidade de pensamento (GUMPERZ, 1989; DIAMOND, 1996, p. 16).

\section{Características discursivas das narrativas interativas na rádio: a reprodução do diálogo, o autoelogio no discurso testemunhal, os marcadores discursivos $e$ as asserções avaliativas}

As narrativas interativas na rádio apresentam o relato de uma história que apresenta um modo de enunciação ancorado na coocorrência entre o Pretérito Imperfeito e o Pretérito Perfeito do Indicativo, tempos da narração que possibilitam a transposição fictiva (FONSECA, 1992, p. 140) para a memória dos factos narrados ou evocados. Uma das características enunciativas fundamentais destas narrativas é a constante referenciação no Presente do Indicativo, que remete para o tempo da enunciação (T0), ancorado na situação de enunciação, permitindo, assim, a referência deítica (ALMEIDA, 2011, p. 45). Esta ancoragem no tempo da enunciação é, regularmente, feita através de asserções que denotam experiências e percepções avaliativas características do discurso testemunhal.

Atentemos no seguinte exemplo:

(1)

Programa: BN

Data: $22 / 04 / 98$

Tema: "Pequenos anúncios de jornal"

Ouvinte $\mathrm{n}^{\mathrm{o}}$. 181, feminino

Ouvinte - Estava já divorciada há uns seis pra sete anos, trabalhava, diziam que qu'eu qu'era muito bonita, ainda hoje dizem, não sei...

- Locutora - Olhe que bom (risos).

Ouvinte - Hoje já estou com sessenta e três anos, mas dizem que eu tenho uma carinha muito engraçada.

- Locutora - Que bom pra si.

Ouvinte - E as minhas colegas, na brincadeira, diziam-me por que é que tu e tal não arranjas tu tão jeitosa tão boa rapariga e tal, por que é que não arranjas! Eh pá, eu tive uma... uma fraca experiência, uma má experiência, e um mau...

Locutora - Não se queria meter noutra pra já. 
Ouvinte - Não me queria meter noutra. E uma vez, uma por brincadeira, aparece-me com um anúncio de jornal e diz-me: olha, por que é que tu não respondes? E a resposta era por meio de telefone, nem era por meio de, de, do próprio jornal...

No exemplo (1), verificamos que a ouvinte realiza um discurso relatado com segmentos no Pretérito Imperfeito que constituem asserções avaliativas: "Estava já divorciada há uns seis pra sete anos, trabalhava, diziam que qu'eu qu'era muito bonita". A dependência contextual (FONSECA, 1992, p. 140) expressa nestas narrativas orais é demonstrada pelos segmentos que remetem para o tempo da enunciação (T0) expresso no Presente do Indicativo: "ainda hoje dizem, não sei...". Regularmente, nas narrativas interativas orais, a ancoragem no presente da enunciação é feita através de uma asserção avaliativa que expressa um ato com o valor ilocutório de autoelogio (implícito), convocado através da voz de uma terceira pessoa do plural “dizem" (ALMEIDA, 2019, p. 250). Seguindo o princípio da modéstia, este mecanismo de convocar outras vozes que elogiam o locutor cria "uma distância epistémica entre o locutor e o elogio" (SPEER, 2012, p. 60, tradução nossa): "Hoje já estou com sessenta e três anos, mas dizem que eu tenho uma carinha muito engraçada”. A ouvinte deste programa de rádio recorre a uma terceira pessoa do plural do verbo declarativo dizer - dizem - para se distanciar do que é dito e poder assim mitigar o autoelogio.

A análise do exemplo (1) permite ainda ilustrar uma outra característica destas narrativas orais: a realização de falas justapostas integradas no discurso relatado com o recurso a expressões aproximativas como "e tal" nos segmentos em discurso direto: "E as minhas colegas, na brincadeira, diziam-me por que é que tu e tal não arranjas tu tão jeitosa tão boa rapariga e tal, por que é que não arranjas!'. No presente exemplo, a expressão aproximativa "e tal" remete, resumindo, para o uso atributivo de expressões predicativas (CAMPOS; XAVIER, 1991, p. 224), como "(ser) tão jeitosa tão boa rapariga e tal": "e tal", implicita uma asserção avaliativa geral que resume todas as expressões atributivas que se integrariam no mesmo campo semântico dos adjetivos intensificados pelos advérbios de intensidade "tão" em "tão jeitosa" e "tão boa". Estas expressões predicativas com adjetivos intensificados constituem o termo localizador do referente (de quem se fala): "rapariga". Este último constitui, na linha de Culioli (1990), o termo localizado (CAMPOS; XAVIER, 1991, p. 296). Sendo um referente de terceira pessoa do singular - "uma não pessoa" (BENVENISTE, 1966) -, este referente remete para um ausente que se torna presente: [eu que era/sou] "uma tão boa rapariga". Do ponto de vista semântico e pragmático, este enunciado estabelece uma distanciação em relação ao que é dito e diz respeito ao Outro de que se fala que constitui a imagem do locutor que está a falar e diz "eu".

Os interlocutores destas narrativas marcam constantemente o seu envolvimento através de estratégias que se reportam a uma "escuta ativa" (COUPLAND \& JAWORSKI, 2003, p. 88). Esta última é denotada pela realização de enunciados que constituem comentários avaliativos (assinalados com uma seta no exemplo 1): "Olhe que bom (risos)", "Que bom pra si. ". As asserções avaliativas ocorrem durante a escuta de uma história narrada por um dos interlocutores, constituindo contribuições para a história (COATES, 2003, p. 132), isto é, são 
segmentos reveladores da construção conjunta ou coconstrução dos rumos discursivos que os participantes realizam e constituem estratégias interativas que denotam o envolvimento conversacional dos participantes, permitindo dar continuidade ao rumo discursivo do interlocutor.

Prototipicamente, nestes contextos interacionais, o alocutário destas narrativas realiza intervenções de continuidade, proferindo asserções-resumo como "Não se queria meter noutra pra já". Estas asserções revelam a escuta atenta e a colaboração com o seu interlocutor: as intervenções de continuidade permitem ceder a vez de elocução de modo a que a ouvinte de rádio prossiga o rumo discursivo da história narrada. Por sua vez, a repetição da asserçãoresumo por parte desta última constitui uma estratégia de estabelecimento do acordo na interação: "Não me queria meter noutra".

Assim, para dar continuidade ao sentido do discurso destes programas de rádio, ocorre, regularmente, o paralelismo estrutural denotado pela "presença de traços gramaticais comuns (e.g. tempo, aspecto, diátese), da mesma ordem de palavras ou da mesma estrutura frásica em fragmentos contíguos" (DUARTE, 2003, p. 110), constituindo um mecanismo de coesão no discurso oral interativo destes programas. O paralelismo sintático entre enunciados repetidos pelos dois intervenientes da comunicação - "Não se queria meter noutra pra já" (locutora de rádio) e "Não me queria meter noutra" (ouvinte) -, com repetições e segmentos em simultâneo (assinalados com o sublinhado), constitui um fenómeno discursivo prototípico do oral interativo que cria coesão sequencial, dando continuidade ao tema da emissão. Tratando-se de um mecanismo de reforço do acordo, denota o envolvimento conversacional dos participantes na interação.

No seio das histórias de vida, é frequente que os ouvintes destes programas produzam também asserções com comentários avaliativos, como podemos observar no seguinte exemplo:

(2)

Programa: BN;

Data: Novembro de 1998;

Tema: "O piropo"; Ouvinte n'. 460, feminino, vendedora

Bem eu quando me apercebi que vinha de frente com eles vi que eles vinham a fazer qualquer qualquer comentário a meu respeito. Senti-me envergonhada, enfim cabisbaixa, e... pronto não dei confiança, mas no momento em que eles se iam a cruzar comigo diz um pra o outro assim, com pronto uma frase muito com muita entoação: "e ainda dizem que as flores que não andam". Pronto, realmente ia um pouquinho arranjada (riso)...

Locutora - Elegante, hã.

No exemplo (2), verificamos que a ouvinte produz um ato com o valor ilocutório de autoelogio que constitui uma valorização da sua face positiva: "Pronto, realmente ia um pouquinho arranjada (riso)...". O emprego do diminutivo em minimizadores ou atenuadores em expressões como "um pouquinho", realizada na sequência "Pronto, realmente ia um pouquinho arranjada (riso)...", constitui o que Claudia Caffi (2000, p. 96) chama de "diminutivo na marcação de imprecisão (fuzziness)". Neste caso, a mitigação está centrada 
sobre o conteúdo proposicional: o mitigador "um pouquinho" torna a referência menos precisa, "reduzindo as obrigações epistémicas para o locutor" (CAFFI, 2000, p. 96) e produzindo, por implicatura conversacional, uma diminuição do valor alto do elogio (ALMEIDA, 2009, p. 54; ALMEIDA, 2019, p. 261), minimizando-o, no quadro do princípio de modéstia interiorizado pelos interlocutores. É este princípio que permite evitar que os locutores não exagerem no autoelogio para não ameaçar a face do Outro. Na linha de Kerbrat-Orecchioni (2005), a valorização ou ameaça dos atos de discurso tem de ser definida em termos de grau. Regularmente, a valorização positiva conjuga-se com estratégias de intensificação quando se direciona para o alocutário, mas nos atos orientados para a valorização da própria face do locutor ou autovalorização, o locutor recorre a estratégias de atenuação que, no quadro do princípio da modéstia, permitem atenuar a ameaça da face positiva do alocutário: "Com efeito, se não é conveniente exaltar a sua própria face é porque um tal comportamento atinge indiretamente, por um movimento inverso de desvalorização implícita, a face do outro" (KERBRAT-ORECCHIONI, 2005, p. 202; tradução nossa). Neste sentido, o diminutivo que ocorre no segmento "um pouquinho arranjada" expressa a delicadeza e enquadra-se no quadro do princípio da modéstia, que constrange o locutor de um ato de autoelogio ("auto-Face Flattering Act") a não valorizar demasiado a sua face positiva. Assim, é frequente que, nas narrativas orais, o diminutivo coocorra com os risos (sinais antiorientadores da ameaça), em atos com valor ilocutório de autoelogio (ALMEIDA, 2019, p. 261), fazendo assim, parte do conjunto de "suavizadores rituais" - « adoucisseurs rituels » (KERBRAT-ORECCHIONI, 2005, p. 210) -, também denominados atenuadores ("softeners"), na análise linguística anglosaxónica (FRASER, 1980).

No exemplo (2), verificamos também que ocorrem usos discursivos de pronto como marcador discursivo: (i) uso com valor conclusivo, em expressões com outros marcadores funcionalmente similares "e... pronto" em "e... pronto não dei confiança”; (ii) uso de pronto de natureza argumentativa, como introdutor de um esclarecimento, de uma precisão (SILVA, 2006, p. 273), expresso no segmento "diz um pra o outro assim, com pronto uma frase"; (iii) uso de um pronto "resumitivo" (SILVA, 2006, p. 271), de natureza textual/discursiva, de estruturação do texto/discurso, semelhante a expressões como "em síntese", que ocorre no segmento "Pronto, realmente ia um pouquinho arranjada (riso)...".

Deste modo, os fenómenos discursivos prototípicos das narrativas interativas são: (i) a ocorrência de falas justapostas em discurso direto; (ii) o uso de expressões aproximativas como "e tal"; (iii) o uso reiterado de asserções avaliativas com suavizadores; (iv) a realização reiterada de comentários avaliativos e de asserções resumo que denotam a escuta atenta dos interlocutores; (v) o uso de repetições sintático-semânticas; (vi) o uso de diminutivos com valor de suavização e/ou mitigação da ameaça da face do alocutário em atos de autoelogio e o mecanismo de distanciamento nestes atos com recurso ao uso do verbo declarativo dizer na terceira pessoa do plural ("dizem que"); (vii) o uso polifuncional de marcadores discursivos como "pronto".

\section{LINHA DÁGUA}




\section{Estratégias de atribuição de credibilidade e de legitimação em conversas na rádio}

A realização de "identidades situadas" (ZIMMERMAN, 1998, p. 100) com valor testemunhal é uma das estratégias que contribui para atribuir credibilidade ao discurso dos ouvintes que entram em antena e, simultaneamente, legitimar a entrada na emissão, como podemos verificar nos seguintes exemplos:

(3)

Programa: BN;

Data: Novembro de 1998;

Tema: "O piropo"; Ouvinte no. 460, feminino, vendedora

Ouvinte - Como está? Eu oiço muito o seu programa eh porque me deito sempre às três da manhã, aliás sou mais uma ouvinte assídua da Rádio Renascença desde as oito da manhã mais ou menos até me deitar.

(4)

Programa: BN

Data: Novembro de 1998

Tema: "Autodidatas"

Ouvinte Feminino; $n^{\circ} .165$

Ouvinte: [Asserção sobre o Tema] Então eu também vou dizer, eu também possome considerar uma autodidata.

Locutora: [Pedido de informação] Então conte-me lá?

Em (3), a ouvinte atribui-se uma identidade discursiva de ouvinte regular do programa: "aliás sou mais uma ouvinte assídua da Rádio Renascença”, que permite justificar a sua entrada no tema da emissão. Em (4), a ouvinte realiza uma asserção avaliativa que permite posicionar-se argumentativamente, como uma ouvinte autorizada a falar sobre o tema da emissão: "eu também posso-me considerar uma autodidata". Estas asserções têm como conteúdo proposicional a necessidade de os ouvintes que participam nestas emissões enquadrarem a sua atividade discursiva com base na determinação de uma identidade discursiva de falante "expert" e com legitimidade não só para emitir uma opinião, mas também para contar uma história de vida que se relaciona com os temas de emissão. Esta estratégia permite dar credibilidade ao discurso que os ouvintes irão desenvolver (ALMEIDA, 2012, p. 152).

Este modo de os ouvintes atribuírem uma identidade discursiva constitui, pois, uma atividade com relevância para a representação da atividade do grupo e é uma forma de os participantes procederem ao desenvolvimento dos eixos argumentativos delineados no discurso, tendo simultaneamente um valor testemunhal. Sendo uma forma de legitimação das opiniões expressas, as identidades assim convocadas funcionam, por conseguinte, como uma estratégia de atribuir credibilidade ao discurso e de o legitimar. Assim, no exemplo (4), a locutora de rádio realiza uma intervenção que permite direcionar ou orientar o rumo discursivo do tema da emissão: "Então conte-me lá?" 
No contexto institucional de emissões de rádio noturnas, esta construção de identidades discursivas permite ainda legitimar as digressões temáticas que, constituindo "desvios" ao tema da emissão, são convocadas como estratégias argumentativas para ilustrar uma asserção proferida sobre o tema em análise.

Atentemos no seguinte exemplo:

(5)

Programa: $B N$

Data: $5 / 5 / 98$

Tema: "A disciplina nas escolas"

Ouvinte Masculino; 32 anos; $n^{\circ} .437$

Ouvinte - Eu eu acho que isso que não está correto, eu acho que hoje em dia os professores haviam de ter muito mais apoio, principalmente dos pais, não era, para... pa dar um... bocado de disciplina ò... òs alunos aos seus alunos nas escolas. Eu entendo isso, qu'até é a minha maneira, não sei se serei antiquado mas (...).

Locutora - (Riso) É a sua forma de pensar e é isso é que nós queremos auscultar também, é a forma das pessoas pensarem.

- Ouvinte - Evidentemente. Olhe minha senhora, eu tenho eu tenho o segundo ano, portanto o segundo ano eh... do ciclo e... e eu tenho e sou um caso muito curioso.

Neste exemplo (5), as identidades discursivas expressas -“eu tenho eu tenho o segundo ano, portanto o segundo ano eh... do ciclo e... e eu tenho e sou um caso muito curioso. Olhe eu tenho eu tenho livros em casa" - assinalam competências específicas relativas ao domínio da oralidade e ao grau de escolaridade. Estas identidades, neste contexto de programas de rádio noturnos, subordinados a temas específicos da vida quotidiana, permitem contar outros eventos paralelos, contribuindo para as digressões temáticas, ao mesmo tempo que funcionam como estratégias de atribuição de credibilidade do discurso, pois denotam que o discurso é vivido, autêntico e testemunhal.

No entanto, por força do carácter institucional destes programas, o foco de atenção tem de ser mantido por mais tempo nestas emissões. Quando as interações revelam digressões temáticas (desvios), os participantes, através do seu saber partilhado e das imagens que constroem uns dos outros (AMOSSY, 1999, p. 135), reconstituem, reinterpretam-nas, reorientam o discurso com o objetivo de fazer a progressão temática. No exemplo (5), a locutora de rádio realiza intervenções de relance do tema: "(Riso) É a sua forma de pensar e é isso é que nós queremos auscultar também”. Estas intervenções permitem estabelecer o foco de atenção, relembrando ao auditório o tema da conversa e imprimindo ao discurso da ouvinte um rumo discursivo.

Com efeito, faz parte do saber comum dos participantes destes programas que todos os ouvintes têm legitimidade para manifestar a sua opinião e contar uma história de vida para a ilustrar. Esta estratégia desenvolvida pelos locutores de rádio constitui uma forma de estabelecer o consenso e o equilíbrio na interação. 


\section{Conclusão}

A análise do funcionamento enunciativo-pragmático das narrativas de experiência de vida que são desenvolvidas em programas de rádio realça os aspetos discursivos que denotam o envolvimento conversacional dos participantes na interação: a construção de um discurso testemunhal de carácter confessional com a produção de identidades discursivas relevantes para a sequencialidade discursiva, no âmbito de um contrato de comunicação mediática, contribui para dar credibilidade ao discurso produzido e para o legitimar. No discurso testemunhal, a ocorrência de fórmulas características do discurso oral interativo com a justaposição de falas e com a realização de segmentos em discurso direto que ocorrem em relatos de discurso indireto, o uso de expressões aproximativas como "e tal" e de marcadores discursivos polifuncionais como "pronto", a ocorrência de asserções avaliativas com suavizadores como "um pouquinho" e com o recurso ao mecanismo de autoelogio, através de expressões de distanciação como "dizem que", são alguns aspetos que revelam a produção de um discurso emotivo que capta a atenção do interlocutor e, consequentemente, do auditório dos programas de rádio de antena aberta.

Assim, é através destas narrativas que os interlocutores constroem as identidades discursivas que os determinam como interlocutores ratificados, intervenientes autorizados a participar no espaço interacional e comunicativo de programas de rádio específicos.

Com efeito, os interlocutores que participam em programas de phone-in na rádio realizam espontaneamente identidades locais, relevantes para a construção de uma imagem de si próprios com um estatuto de interlocutor validado ou ratificado interacionalmente. Os participantes ratificados são identificados em função de parâmetros específicos relacionados com a sua vida profissional, a sua faixa etária ou com aspetos que dizem respeito à sua mundividência, enquadrando-os no relato de uma história de vida e constituindo, assim, testemunhos de uma experiência vivida que querem partilhar com o locutor de rádio e com o auditório dos programas.

O discurso destes contextos mediáticos realça que os participantes estabelecem uma comunidade de discurso constituída por locutores de rádio, ouvintes e auditório.

Em suma, a análise da irrupção de narrativas de experiência de vida no discurso interativo oral na rádio salienta que é através da comunicação que os falantes se ratificam mutuamente como interlocutores credíveis e legítimos para se posicionarem em relação a um tema da emissão. Com as narrativas de experiência de vida na rádio, os participantes inscrevemse, assim, na práxis social, constituindo-se como interlocutores autorizados, com credibilidade e legitimidade, para proferirem um discurso sobre os temas das emissões e, desta forma, produzem um discurso que capta a atenção do auditório. 


\section{Referências}

ALMEIDA, C. A. Processos de figuração e manutenção da ordem interaccional: estratégias de mitigação no quadro do sistema de delicadeza desenvolvido pelos participantes de programas de rádios específicos. In: FIÉIS, A.; COUTINHO, M. Textos seleccionados. XXIV Encontro Nacional da Associação Portuguesa de Linguística. Lisboa: Colibri, 2009, p. 43- 60.

ALMEIDA, C. A. Aspectos semânticos e pragmáticos da co-construção de identidades discursivas em narrativas de experiência de vida produzidas por participantes de emissões nocturnas de rádio. In: COSTA, A.; FALÉ, I.; BARBORSA, P. Textos Seleccionados. XXVI Encontro Nacional da Associação Portuguesa de Linguística. Lisboa: APL, p. 35-48, 2011.

ALMEIDA, C.A. A construção da ordem interaccional na rádio: Contributos para uma análise linguística do discurso em interacções verbais. Porto: Afrontamento, 2012.

ALMEIDA, C. A. Rituais verbais, envolvimento conversacional e ordem interaccional: a construção de trocas discursivas em programas de rádio. Cadernos de Ciências Sociais, n. 27, p. 93-130, 2014.

ALMEIDA, C.A. Discourse strategies of mitigation in an oral corpus of narratives of life experience collected in interviews. In: ROULSTON, K. (Ed.) Interactional Studies of Qualitative Research Interviews. Amsterdam/ Philadelphia: John Benjamins, p. 239-268, 2019.

AMOSSY, R. L'ethos au carrefour des disciplines : rhétorique, pragmatique, sociologie des champs » In : Amossy, R. (org.) Images de soi dans le discours. La construction de l'ethos. Paris : Delachaux et Niestlé, p. 127-154, 1999.

ANDRÉ-LAROCHEBOUVY, D. La Conversation quotidienne. Paris : Didier, 1984.

ANTAKI, C.; WIDDICOMBE, S. (Eds.). Identities in talk. London: Sage, 1998.

BENVENISTE, E. Problèmes de linguistique générale, I. Paris : Gallimard, 1966.

BONNAFOUS, S.; TOURNIER, M. Analyse du discours, lexicométrie, communication et politique. Langages, n. 117, p. 67-81, 1995.

CAFFI, C. Aspects du calibrage des distances émotives entre rhétorique et psychologie. In : PLANTIN, C. ; DOURY, M. ; TRAVERSO, V. (Orgs.). Les émotions dans les interactions. Lyon : Presses Universitaires de Lyon, p. 89-104, 2000.

CAMPOS, H. C. ; XAVIER, M. F. Sintaxe e Semântica do Português. Lisboa : Universidade Aberta, 1991.

CHARAUDEAU, P. (ed.) Aspects du discours radiophonique. Paris : Didier, 1984.

CHARAUDEAU, P. Une analyse sémiolinguistique du discours. Langages, n. 117, p. 96-111, 1995.

COATES, J. Men talk. Cornwall: Blackwell, 2003.

COUPLAND, J.; JAWORSKI, A. Transgression and intimacy in recreational talk narratives. Research on language and social interaction, v. 36, n. 1, p. 85-106, 2003.

CULIOLI, A. Pour une linguistique de l'énonciation. Paris: Ophyrs, 1990.

DIAMOND, J. Status and power in verbal interaction. A study of discourse in a close-knit social network. Amesterdão/Filadélfia: John Benjamins, 1996.

\section{LINHA DÁGUA}


DUARTE, I. Aspectos linguísticos da organização textual. In: MATEUS, M. H.; BRITO, A. M.; DUARTE, I.; FARIA, I. H. Gramática da Língua Portuguesa. Lisboa: Caminho, 2003.

EDWARDS, D. Emotion. In: WETHERELL, M.; TAYLOR, S.; YATES, S. J. (Eds.). Discourse theory and practice. A reader. London: Sage, 2001, p. 236-246.

FONSECA, F.I. Deixis, tempo e narração. Porto: Fundação Engenheiro António de Almeida, 1992.

FRASER, B. Conversational mitigation. Journal of Pragmatics, v. 4, n. 4, p. 341-350, 1980.

GIBBS, R. W. Situational conventions and requests. In FORGAS, J.. P. (Ed.). Language and social situations. New York: Springer-Verlag, p. 97-110, 1985.

GOFFMAN, E. Interaction Ritual: Essays on Face-to-Face Behavior. New York: Doubleday Anchor, 1967.

GOFFMAN, E. Forms of talk. Philadelphia: University of Pennsylvannia Press, 1981.

GOFFMAN, E. Façons de parler. Paris : Minuit, 1987.

GOODWIN, C. Conversational organization: interaction between speakers and hearers. New York: Academic Press, 1981.

GUMPERZ, J. The sociolinguistic basis of speech act theory. Versus, quaderni di studi semiotici, 26/27, p. 101-121, 1980.

GUMPERZ, J. Discourse strategies. Cambridge: Cambridge University Press, 1982.

GUMPERZ, J. Sociolinguistique interactionnelle. Une approche interprétative. La Réunion : L'Harmattan, 1989.

KERBRAT-ORECCHIONI, C. Les interactions verbales, I. Paris : Armand Colin, $3^{\text {ème }}$ édition, 1998.

KERBRAT-ORECCHIONI, C. Le discours en interaction. Paris : Armand Colin, 2005.

LACOSTE, M. La narrativisation dans une situation d'interview. Études de Linguistique Appliquée, n. 36, p. 50-62, 1986.

MAINGUENEAU, D. L'analyse du discours. Paris : Hachette, 1991.

NASCIMENTO, M. F.; BACELAR, M. F.do; RIVENC, P.; CRUZ, M. L. S. da. Português fundamental, métodos e documentos. Tomo 1 - inquérito de frequência. Lisboa: INIC, CLUL, 1987.

NORRICK, N. R. Conversational narrative. Storytelling in everyday talk. Amsterdam/ Philadelphia : John Benjamins, 2010.

OCHS, E.; CAPPS, L. Living narrative. Creating lives in everyday storytelling. Cambridge : Harvard University Press, 2001.

PLANTIN, C. ; DOURY, M. ; TRAVERSO, V. (Orgs.). Les émotions dans les interactions. Lyon : Presses Universitaires de Lyon, 2000.

SACKS, H. Lectures on conversation, vol. I, II. Oxford/ Cambridge: Blackwell, 1995.

SIFIANOU, M. The use of diminutives in expressing politeness: Modern Greek Versus English. Journal of pragmatics, v. 17, n. 2, p. 155-173, 1992.

SILVA, A. S. O mundo dos sentidos em Português. Coimbra: Almedina, 2006. 
SPEER, S. The interactional organization of self-praise. Social Psychology Quarterly, v. 75, n. 1, p. 52-79, 2012.

TANNEN, D. (Ed.) Coherence in spoken and written discourse. Norwood: Ablex, 1986.

TANNEN, D. Talking voices: repetition, dialogue and imagery in conversational discourse. Cambridge: Cambridge University Press, 1989.

TANNEN, D. The relativity of linguistic strategies: rethinking power and solidarity in gender and dominance. In: WETHERELL, M.; TAYLOR, S.; YATES, S. J. (Eds.). Discourse theory and practice. A reader. London: Sage, 2001, p. 150-166.

THORNBORROW, J. Authenticating talk: building public identities in audience participation broadcasting. Discourse studies, v. 3, n. 4, p. 459-479, 2001.

VAN DIJK, T. A. Cognitive situation models in discourse production. In: FORGAS, J. P. (ed.). Language and Social Situations. New York: Springer-Verlag, 1985.

VERSCHUEREN, J. El regreso de la Pragmática al significado: comentarios sobre la dinámica de la comunicación, los grados de prominencia y la transparencia comunicativa. In: ROYO, L. M.; WHITTAKER, R. Poder - decir o el poder de los discursos. Madrid: Arrecife, Ediciones de la Universidad Autónoma de Madrid, 1998, p. 235-279.

ZIMMERMAN, D. H. Identity, context and interaction. In: ANTAKI, C.; WIDDICOMBE, S. (Eds.). Identities in talk. London: Sage, 1998, p. 87-106.

Recebido: 26/01/2021.

Aprovado: 05/02/2021. 